\title{
IRF1 regulates the progression of colorectal cancer via interferon-induced proteins
}

\author{
XIAOHUI XU ${ }^{1-4^{*}}$, YONG WU $^{1 *}, \mathrm{KE} \mathrm{YI}^{3^{*}}, \mathrm{YAN} \mathrm{HU}^{3}$, WEIQUN DING ${ }^{4}$ and CHUNGEN XING ${ }^{1}$ \\ ${ }^{1}$ Department of General Surgery, The Second Affiliated Hospital of Soochow University, Suzhou, Jiangsu 215004; \\ ${ }^{2}$ Department of General Surgery and ${ }^{3}$ Central Laboratory, The First People's Hospital of Taicang, \\ Taicang Affiliated Hospital of Soochow University, Suzhou, Jiangsu 215400, P.R. China; \\ ${ }^{4}$ Department of Pathology, University of Oklahoma Health Science Center, Oklahoma City, OK 73104, USA
}

Received November 13, 2020; Accepted March 17, 2021

DOI: $10.3892 /$ ijmm.2021.4937

\begin{abstract}
Radiation is one of the main methods for the treatment of colorectal cancer (CRC) before or after surgery. However, radiotherapy tolerance of patients with $\mathrm{CRC}$ is often a major concern. Interferon regulatory factor 1 (IRF1) is a member of the IRF family and is involved in the development of multiple diseases, including tumors. The present study investigated the role of IRF1 in the development and radiation sensitivity of CRC. Immunohistochemistry was performed to examine the expression levels of IRF1 in tissue samples from patients with CRC, as well as in nude mice. MTT, 5-ethynyl-20-deoxyuridine, colony formation, cell cycle alteration and apoptosis assays were performed in CRC cell lines. Western blotting and immunofluorescence were used to detect the expression levels of a series of proteins. RNA sequencing was applied to identify genes whose expression was upregulated by IRF1 overexpression. Xenograft nude mouse models and hematoxylin and eosin staining were used to validate the present findings in vivo. It was revealed that the expression levels of IRF1 were significantly lower in CRC tissues than in adjacent tissues. IRF1 upregulation inhibited cell proliferation and colony formation, caused $\mathrm{G}_{1}$ cell arrest, promoted cell apoptosis, and enhanced the sensitivity of CRC cells to X-ray irradiation. The role of IRF1 in promoting the radiosensitivity of CRC was further demonstrated in nude mice with CRC xenografts. In addition, RNA sequencing revealed that overexpression of IRF1 in CRC cells significantly increased the expression levels of interferon-induced protein family members interferon $\alpha$ inducible protein 6 ,
\end{abstract}

Correspondence to: Dr Chungen Xing, Department of General Surgery, The Second Affiliated Hospital of Soochow University, 1055 Sanxiang Road, Suzhou, Jiangsu 215004, P.R. China

E-mail: xingcg@suda.edu.cn

${ }^{*}$ Contributed equally

Key words: CRC, IRF1, radiosensitivity, IFN- $\gamma$, interferon-induced proteins interferon induced transmembrane protein 1 and interferon induced protein 35 (fold change $>2.0$ ). In summary, the present study demonstrated that the upregulation of IRF1 inhibited the progression and promoted the radiosensitivity of CRC, likely by regulating interferon-induced proteins.

\section{Introduction}

Colorectal cancer (CRC) is the fourth leading cause of cancer-associated mortality worldwide (1). According to the American Cancer Society, there were 145,600 new cases of CRC and 51,020 associated deaths in the United States in 2019, and it ranked third in terms of incidence among all types of cancer (2). Additionally, the incidence and mortality rate of CRC have increased during the past decade in China (3). At present, radiotherapy is recognized as one of the main adjuvant treatment methods for CRC surgery (4). However, postoperative recurrence and metastasis of the tumor still occur due to radiation tolerance (5). Therefore, identifying related biological targets by which the radiosensitivity of CRC can be improved is a topic of great interest.

Interferon regulatory factor 1 (IRF1) is a member of the IRF family and can be activated by cytokines, such as IFN- $\gamma$, TNF- $\alpha$ and interleukins-1-6, which are involved in the regulation of various cytokines (IL-4, IL-5, IL-12 and IL-13) and immune cells (Th1, Th2 and Th9) (6,7). Furthermore, studies have demonstrated that differences in the sensitivity of IRF1 to IFN- $\gamma$ responses can lead to different clinical outcomes $(8,9)$. IRF1 has been demonstrated to be involved in the pathogenesis of different types of cancer, including breast cancer (10), cervical cancer $(11,12)$, hepatocellular carcinoma (13), pancreatic ductal adenocarcinoma (14), prostate cancer $(15,16)$ and CRC $(17,18)$. It has been revealed that there is positive feedback regulation between IRF1 and microRNA-29b, which could promote the sensitivity of CRC cells to IFN- $\gamma$ (17). Blocking this feedback regulation inhibits the growth and metastasis of CRC (17). Hong et al (18) reported that IRF1 suppresses CRC metastasis and proliferation by promoting Ras association domain-containing protein 5 expression and inhibiting the RAS-RAC1 signaling pathway.

In addition, previous studies have documented that IRF1 affects tumor radiation therapy $(11,19,20)$ : One study revealed 
that nuclear IRF1 expression is higher in patients with cervical cancer with a complete response to radio/chemotherapy than in patients with only a partial response to therapy (11). Chen et al (19) found that IRF1 expression is lower in radiation-tolerant cells than in radiation-sensitive head and neck squamous tumor cells. Furthermore, IRF1 is an important transcription factor for cytosolic DNA sensing-mediated type III IFN production induced by gamma rays in CRC cells (20). Therefore, it is clear that IRF1 is involved in the radiotherapy of tumors. However, to the best of our knowledge, it is unclear how IFN- $\gamma$-mediated IRF1 influences the development and radiotherapy of CRC. The present study investigated the role of IRF1 in the progression and radiosensitivity of CRC. The present study demonstrated that the upregulation of IRF1 inhibited CRC progression and promoted the sensitivity of CRC to X-rays in both in vitro and in vivo experiments.

\section{Materials and methods}

Tissue samples. For immunohistochemistry analysis, 200 samples from patients with CRC and 31 matched adjacent tissues were collected at The Second Hospital of Wuxi (Wuxi, China) between January 2010 and December 2012. Among the 200 patients, there were 142 male patients and 58 female patients. Their age ranged between 40 and 83 years, the mean age was 66.21 years and the median age was 66 years. All specimens were obtained during resection. Patients who had undergone radiotherapy or chemotherapy were excluded. Matched adjacent normal tissues were obtained $>2 \mathrm{~cm}$ away from the tumor. All patients provided signed, informed consent for their tissues to be used for scientific research. Ethical approval for the study was obtained from Ethics Committee of The Second Hospital of Wuxi (approval no. KY-2020-001; Wuxi, China). All diagnoses were based on pathological and/or cytological evidence. The histological features of the specimens were evaluated by a senior pathologist according to the classification criteria from the World Health Organization (21).

Immunohistochemistry. Immunohistochemistry staining and the stained section scoring methods were described in a previous study (22). IRF1 (dilution, 1:500; cat. no. ab232861; Abcam) and Bcl-2 (dilution, 1:100; cat. no. ab182858; Abcam) antibodies were used. The secondary antibody was horseradish peroxidase-labeled goat anti-rabbit IgG $(\mathrm{H}+\mathrm{L})$ (dilution, 1:500; cat. no. A0208; Beyotime Institute of Biotechnology).

Human Protein Atlas database. The results of IRF1 in CRC were validated using the Human Protein Atlas database, which is a database for cancer and normal protein expression in tissues and the analysis of patient survival (23). The specific steps were as follows: The www.proteinatlas.org website was used to enter 'IRF1' in the search field. Subsequently, 'Pathology' was selected, and 'Colorectal cancer' was selected in 'RNA EXPRESSION OVERVIEW' to obtain the survival analysis result and figure.

Cell culture, treatment, transfection, infection and irradiation. Human CRC-derived HT29 and LoVo cell lines were resuscitated and resuspended in RPMI 1640 medium (HyClone; Cytiva), while HCT116, CCL244 and SW480 were resuspended in high-glucose DMEM (HyClone; Cytiva) supplemented with
$10 \%$ (v/v) FBS (Biological Industries). Our previous study revealed that CCL244 and SW480 cells were relatively radiation-resistant cell lines among seven types of CRC cells: HT29, LoVo, Hce8693, CaCo2, HCT116, CCL244 and SW480 (24). The present study mainly explored how to enhance the radiation sensitivity of CRC. Therefore, these two types of cells were used for in vitro experiments. All cells were obtained from The Cell Bank of Type Culture Collection of The Chinese Academy of Sciences and maintained in medium supplemented with $10 \% \mathrm{FBS}$ and $100 \mathrm{U} / \mathrm{ml}$ penicillin-streptomycin at $37^{\circ} \mathrm{C}$ with $5 \% \mathrm{CO}_{2}$. IFN- $\gamma$ (ProteinTech Group, Inc.) was added to the culture medium at $10 \mathrm{ng} / \mathrm{ml}(17)$ at $0,0.25,0.50,1.50$ and $2.00 \mathrm{~h}$.

For plasmid transfection, the cells were grown in a 6-well culture plate to $70-80 \%$ confluence and then transfected with $2.5 \mu \mathrm{g}$ plasmids for $20 \mathrm{~min}$ [either short hairpin RNA (shRNA)-negative control (NC), 5'-TTCTCCGAACGTGT CACGTTTCAAGAGAACGTGACACGTTCGGAGAATTTTTT-3' or shRNA-IRF1, 5'-GGCTCATCTGGATTAATA AA GTTCAAGAGACTTTATTAATCCAGATGAGCCTTTTTT-3'; Vigene Biosciences] using Lipofectamine 2000 at room temperature (Invitrogen; Thermo Fisher Scientific, Inc.) according to the manufacturer's protocol. After $48 \mathrm{~h}$, the cells were collected for assays.

For viral infection, the adenovirus expression vectors IRF1 (Ad-IRF1) and negative control (Ad-NC) were obtained from Hanbio Biotechnology Co., Ltd. The cells were infected with Ad-IRF1 and Ad-NC (multiplicity of infection, 3) for $4 \mathrm{~h}$ and then the medium was changed according to the manufacturer's protocol. The cells were used for relevant experiments at $48 \mathrm{~h}$ after infection. Furthermore, the present study mainly focused on the inhibitory effect of IRF1 on CRC and the enhanced radiation sensitivity of CRC. Therefore, the cells were divided into two groups in in vitro experiments: Ad-NC and Ad-IRF1.

SW480 and CCL244 cells were irradiated with an X-ray linear accelerator ( $\mathrm{Rad}$ Source Technologies) at a dose rate of $1.15 \mathrm{~Gy} / \mathrm{min}$.

Cell proliferation assay. After cells infected with Ad-NC and Ad-IRF1, SW480 or CCL244 cells were seeded into 96-well plates at a density of $5 \times 10^{3}$ cells per well with eight parallel wells per group. At 24, 48 and $72 \mathrm{~h}$ after 6 Gy X-ray treatment, cell proliferation was measured using the MTT assay. Briefly, $20 \mu \mathrm{l}$ MTT solution $(5 \mathrm{mg} / \mathrm{ml})$ and $100 \mu \mathrm{l}$ complete medium were added to each well, and the cells were incubated for $4 \mathrm{~h}$ at $37^{\circ} \mathrm{C}$. The medium was then aspirated, and $150 \mu \mathrm{l}$ dimethyl sulfoxide was added to dissolve the crystals. The optical density (OD) was measured at $490 \mathrm{~nm}$ using a microplate reader (Bio-Rad Laboratories, Inc.). The viability index was calculated as the experimental OD value/the control OD value. Three independent experiments were performed in quadruplicate.

Colony formation assay. The cells were seeded into 6-well plates at different densities of $4 \times 10^{2}$ (for both cell lines with 0 Gy) and $8 \times 10^{3}$ (for CLL244 cells with 6 Gy and SW480 cells with 4 Gy) cells per well with three parallel wells per group. After $24 \mathrm{~h}$, CCL244 cells were exposed to X-rays with different irradiation doses of 0 and $6 \mathrm{~Gy}$, and SW480 cells were exposed to X-rays with different irradiation doses of 0 and 4 Gy. After 14 days of incubation at $37^{\circ} \mathrm{C}$, the colonies were fixed with anhydrous methanol $(100 \%)$ at room temperature for $15 \mathrm{~min}$ and stained 
with Giemsa at room temperature for $30 \mathrm{~min}$, and those with a minimum of 50 viable cells were counted under a light microscope (Leica Microsystems $\mathrm{GmbH}$ ). This process was repeated three times. The cloning efficiency was calculated as the ratio of the number of colonies formed divided by the total number of cells plated. The GraphPad software (version 9.0.0; GraphPad Software, Inc.) was used to analyze the cloning efficiency.

5-Ethynyl-20-deoxyuridine (EdU) incorporation assay. The Cell-Light EdU DNA Cell Proliferation kit (Guangzhou RiboBio Co., Ltd.) was used to determine the proliferation rate of CCL244 or SW480 cells after treatment according to the manufacturer's protocols. Briefly, the cells were incubated at $37^{\circ} \mathrm{C}$ with $50 \mu \mathrm{M} \mathrm{EdU}$ for $2 \mathrm{~h}$ prior to fixation with $4 \%$ paraformaldehyde for $30 \mathrm{~min}$ at room temperature, $0.5 \%$ TritonX-100 permeabilization for $10 \mathrm{~min}$ at room temperature and EdU staining for $30 \mathrm{~min}$ at room temperature. The cell nuclei were stained with Hoechst 33342 at a concentration of $5 \mu \mathrm{g} / \mathrm{ml}$ for $30 \mathrm{~min}$ at room temperature, and the cells were examined under a fluorescence microscope (Leica Microsystems $\mathrm{GmbH}$ ). The GraphPad software (version 9.0.0; GraphPad Software, Inc.) was used to analyze the proportion of red to blue.

Flow cytometric analysis of cell apoptosis. Following conventional digestion, cells in the logarithmic growth phase were used to prepare a single cell suspension, $2 \times 10^{5}$ cells $/ \mathrm{ml}$ were seeded into 6-well plates with three parallel wells per group. At $48 \mathrm{~h}$ after irradiation ( 0 and $6 \mathrm{~Gy}$ ), all cells were collected and centrifuged at $300 \mathrm{x} \mathrm{g}$ for $5 \mathrm{~min}$ at $4^{\circ} \mathrm{C}$. The supernatant was discarded after washing with PBS, and centrifugation at $300 \mathrm{x}$ g for $5 \mathrm{~min}$ at $4^{\circ} \mathrm{C}$ was repeated twice. The cells were then stained with fluorescein FITC-conjugated Annexin V (Shanghai Yeasen Biotechnology Co., Ltd.) and PI (Shanghai Yeasen Biotechnology Co., Ltd.), and directly analyzed using the flow cytometry software equipped in the machine (BD FACSVerse; Becton-Dickinson and Company). The ratio of both early and late apoptotic cells was counted. The GraphPad software (version 9.0.0; GraphPad Software, Inc.) was used to statistically analyze the data (24).

Flow cytometric analysis of the cell cycle. At $48 \mathrm{~h}$ after irradiation with 0 and $8 \mathrm{~Gy}$, cells infected with Ad-NC and Ad-IRF1 in logarithmic growth phase were collected and fixed with $70 \%$ precooled ethanol at $4^{\circ} \mathrm{C}$ overnight. After staining with propidium iodide $(10 \mu \mathrm{g} / \mathrm{ml}$; Shanghai Yeasen Biotechnology Co., Ltd.) in the dark for $30 \mathrm{~min}$ at $37^{\circ} \mathrm{C}$, flow cytometry was performed on the BD FACSCalibur Flow Cytometer system (Becton-Dickinson and Company), and the cell cycle distribution was analyzed using FlowJo software (version 7.6; Becton-Dickinson and Company) and ModFit LT software (version 3.2; Becton-Dickinson and Company) (22).

RNA sequencing analysis. Total RNA from three paired Ad-IRF1 and Ad-NC CCL244 cell lines was isolated with an RNA Isolation kit (cat. no. 12183018A, Ambion; Thermo Fisher Scientific, Inc.). RNA purity and quantification were evaluated using a NanoDrop 2000 spectrophotometer (Thermo Fisher Scientific, Inc.). RNA integrity was assessed using the Agilent 2100 Bioanalyzer (Agilent Technologies, Inc.). Subsequently, using RNA with an initial quality of $4 \mu \mathrm{g}$ as raw material for sequencing, the libraries were constructed using
TruSeq Stranded mRNA LT Sample Prep kit (Illumina, Inc.) according to the manufacturer's protocols. The transcriptome sequencing and analysis were conducted by OE Biotech Co., Ltd. The libraries were sequenced on an Illumina HiSeq X Ten platform and $150 \mathrm{bp}$ paired-end reads were generated. The clean reads were mapped to the human genome using HISAT2 (25). FPKM (26) value of each gene was calculated using Cufflinks (27), and the read counts of each gene were obtained by HTSeq-count (28). Differential expression analysis was performed using the DESeq (2012) R package (29). $\mathrm{P}<0.05$ and fold change $>2$ or fold change $<0.5$ was set as the threshold for significantly differential expression. Hierarchical cluster analysis of differentially expressed genes (DEGs) was performed to explore gene expression patterns. GO enrichment (30) and KEGG (31) pathway enrichment analysis of DEGs were performed respectively using $\mathrm{R}$ based ( $\mathrm{R}$ 3.6.2; https:/cran.r-project.org/bin/windows/base/old/3.6.2/) on the hypergeometric distribution. All sequencing procedures and analyses were performed at OE Biotech Co., Ltd.

Immunofluorescence. The treated cells were placed in 24-well plates with circular slides, up to 50-60\% confluence fixed with $4 \%$ paraformaldehyde at room temperature for $10 \mathrm{~min}$ after $\mathrm{X}$-ray radiation for 0,3 and $6 \mathrm{~h}$, and then treated with $1 \%$ Triton X-100 for $10 \mathrm{~min}$ at room temperature. After blocking with $1 \%$ BSA (Beyotime Institute of Biotechnology) for $1 \mathrm{~h}$ at room temperature, the samples were incubated with the IRF1 antibody (dilution, 1:1,000; cat. no. ab26109; Abcam) overnight at $4^{\circ} \mathrm{C}$, and then incubated with FITC-conjugated goat anti-rabbit secondary antibody (dilution, 1:1,000; cat. no. A0562; Beyotime Institute of Biotechnology) for $2 \mathrm{~h}$ at room temperature. The nuclei were stained with DAPI (Sigma-Aldrich; Merck KGaA). The cells were observed under a confocal microscope (Olympus Corporation).

Western blotting. Cells were lysed in 1X RIPA (cat. no. P0013B; Beyotime Institute of Biotechnology) lysis buffer. The total protein concentration was detected using a BCA kit (cat. no. P0010S; Beyotime Institute of Biotechnology). The samples were centrifuged at $12,000 \times \mathrm{g}$ for $15 \mathrm{~min}$ at $4^{\circ} \mathrm{C}$ and then boiled, and $\sim 20 \mu \mathrm{g}$ protein/lane was loaded onto 12 or $15 \%$ SDS-PAGE (cat. no. P0012A; Beyotime Institute of Biotechnology) gels. The electrophoresed samples were then transferred onto PVDF membranes (cat. no. IPVH00010; EMD Millipore), which were then blocked with PBS (HyClone; Cytiva)/Tween 20 (0.1\%; VWR International, LLC) containing 5\% BSA (Beyotime Institute of Biotechnology) for $1 \mathrm{~h}$ at room temperature. The membranes were incubated with antibodies against IRF1 (dilution, 1:1,000; cat. no. ab26109; Abcam), interferon induced protein 35 (IFI35; dilution, 1:1,000; cat. no. ab233415; Abcam), interferon $\alpha$ inducible protein 6 (IFI6; dilution, 1:1,000; cat. no. ab192314; Abcam), Bcl-2 (dilution, 1:1,000; cat. no. ab182858; Abcam), cleaved caspase-3 (dilution, 1:1,000; cat. no. ab2302, Abcam), cleaved caspase-9 (dilution, 1:1,000; cat. no. ab2324; Abcam), interferon induced transmembrane protein 1 (IFITM1; dilution, 1:1,000; cat. no. 60074-1-Ig; ProteinTech Group, Inc.), Bax (dilution, 1:1,000; cat. no. 5023S, Cell Signaling Technology, Inc.), $\beta$-actin (dilution, 1:1,000; cat. no. AF0003; Beyotime Institute of Biotechnology), GAPDH (dilution, 1:1,000; cat. no. AF0006; Beyotime Institute of Biotechnology) and 
Tubulin (dilution, 1:1,000; cat. no. AT819; Beyotime Institute of Biotechnology) overnight at $4^{\circ} \mathrm{C}$. Goat anti-mouse secondary antibodies (dilution, 1:1,000; cat. no. A0286) and goat anti-rabbit secondary antibodies (dilution, 1:1,000; cat. no. A0277) were purchased from Beyotime Institute of Biotechnology. The membranes were incubated with the appropriate secondary antibody for $1 \mathrm{~h}$ at room temperature. After being washed, the membranes were incubated with enhanced chemiluminescence (ECL) stable peroxide solution (Beyotime Institute of Biotechnology). All blots were visualized using a G: BOX Chemi XRQ gel doc system (Syngene Europe) at room temperature and Image J (version 1.8.0; National Institutes of Health) was used for densitometry.

Animal experiments and irradiation. A total of 25 male BALB/c nude mice (4 weeks old and weighing 18-22 g) were purchased from Shanghai SLAC Laboratory Animal Co., Ltd. The mice were maintained under standard laboratory conditions with a 12-h light-dark cycle at a controlled temperature $\left(21-23^{\circ} \mathrm{C}\right)$ and humidity (40-60\%), and given access to sterilized food and water in a specific pathogen-free environment throughout all experiments. All experimental procedures were performed in accordance with the Guide for the Use and Care of Laboratory Animals from the National Institutes of Health (32). For the subcutaneous injection, CCL244 cells $\left(5 \times 10^{4}\right)$ were suspended in $100 \mu \mathrm{l}$ PBS and then inoculated subcutaneously into the right posterior flank region of BALB/c nude mice. The mice were divided into five groups: i) Control group without treatment; ii) Ad-IRF1 group; iii) Ad-NC group; iv) shRNA-IRF1 group; and v) shRNA-NC group. Each group consisted of five nude mice. Two-dimensional measurements were taken with an electronic caliper every 3 days, and the tumor volume (in $\mathrm{mm}^{3}$ ) was calculated using the following formula: Volume $=a \mathrm{x} \mathrm{b}^{2} / 2$, where $\mathrm{a}$ is the longest diameter, and $\mathrm{b}$ is the shortest diameter of the tumor. When the tumor volume reached $80 \mathrm{~mm}^{3}$ on the fifth day, the local tumor was irradiated with 8 Gy X-ray. Tumor volume was then measured every 4 days, mice were sacrificed on the 29th day, and tumors were frozen at $-80^{\circ} \mathrm{C}$ or fixed in $10 \%$ formalin at room temperature overnight and subjected to routine histological examination. Formalin-fixed subcutaneous tumors were used for the following immunohistochemistry (for Bcl-2) experiments. Next, liver and lung metastasis models were established by tail vein injection of IRF1-upregulated/IRF1-downregulated and control CCL244 cells resuspension solutions, $10^{6}$ cells in $100 \mu$ l PBS per nude mouse (the grouping was the same as aforementioned). The time interval between injection and the end of experiment was from injection to the specific humane endpoints. The maximum time interval was 35 days. For metastatic tumor models, the specific humane endpoints were: Rapid weight loss or emaciation characterized by anemia, hunched posture, ungroomed appearance and lethargy (33). Liver metastatic tumors were frozen at $-80^{\circ} \mathrm{C}$ or fixed in $10 \%$ formalin at room temperature overnight and subjected to routine histological examination. HE and Immunohistochemistry for Bcl-2 were performed subsequently. The present study was approved by the Institutional Animal Care and Use Committee of Soochow University (Suzhou, China). The method of sacrifice of the animals was as follows: The nude mouse was placed into the euthanasia box, and carbon dioxide was infused into the box at a rate of $10-30 \%$ of the solvent in the euthanasia box per min. It was ensured that the nude mouse did not move, had no breathing and had dilated pupils. The carbon dioxide was turned off, followed by observation for 2 min to confirm that the nude mouse was dead.

The nude mice were irradiated on the fifth day after cell injection with an X-ray linear accelerator (Varian Clinac CX; Varian Medical Systems, Inc.) at a single dose of $8 \mathrm{~Gy}$ with a fixed dose rate of $300 \mathrm{MU} / \mathrm{min}$ at a temperature of $23 \pm 0.5^{\circ} \mathrm{C}$.

Hematoxylin and eosin $(H \& E)$ staining. Liver tissues and lung tissues were fixed in $10 \%$ neutral-buffered formalin for $24 \mathrm{~h}$ at room temperature and embedded in paraffin. Paraffin sections $(\sim 3 \mu \mathrm{m})$ were deparaffinized and heat-treated with citrate buffer, $\mathrm{pH} 6.0$, for $7 \mathrm{~min}$ following an epitope retrieval protocol. The sections of the subcutaneous tumor and liver were stained with $\mathrm{H} \& \mathrm{E}$ (hematoxylin, $5 \mathrm{~min}$; and eosin, $1 \mathrm{~min}$ ) at room temperature. All slides were examined under a light microscope (Leica Microsystems $\mathrm{GmbH}$ ) and images were captured. Representative images were randomly selected from each sample.

Statistical analysis. The data were analyzed using an unpaired two-sided Student's t-test to determine statistical significance. When more than two groups were compared, one-way ANOVA was adopted followed by Tukey's post hoc test. For all in vitro experiments, five biological replicates were analyzed. For all in vivo experiments, three biological replicates were analyzed for each condition. Statistical analysis was performed using Prism 6.01 software (GraphPad Software, Inc.). Data are presented as the mean \pm standard error of the mean. $\mathrm{P}<0.05$ was considered to indicate a statistically significant difference.

\section{Results}

IRF1 expression is downregulated in CRC tissues and positively associated with the survival rate. Immunohistochemical staining was performed for $200 \mathrm{CRC}$ tissues and 31 matched tumor-adjacent tissues. The results revealed that IRF1 expression was weaker in CRC tissues compared with in adjacent tumor tissues. In addition, IRF1 was expressed in both the cytoplasm (green arrow) and nucleus (red arrow) (Fig. 1A). The histopathological scores indicated that IRF1 expression in CRC tissues was significantly lower than that in adjacent tissues (Fig. 1B). The present study further searched the Human Protein Atlas database and identified that the 5-year survival rate of patients with high IRF1 expression was significantly higher than that of patients with low IRF1 expression (Fig. 1C). Therefore, IRF1 expression was lower in the tumor tissues and its high expression was associated with improved survival of the patients.

Both IFN- $\gamma$ and $X$-rays induce IRFI expression. Western blotting was used to detect the expression levels of IRF1 in different CRC cells, and it was found that there was no significant difference in the expression levels of IRF1 in different cell lines (Fig. S1). Based on the results of a previous study (24), two cell lines (CLL244 and SW480) were used in in vitro experiments. Consistent with a previous study (17), the present study identified that IFN- $\gamma$ induced IRF1 expression in colon cancer cells. IRF1 expression gradually increased after IFN- $\gamma$ treatment and started to rise within $1 \mathrm{~h}$, as demonstrated by 

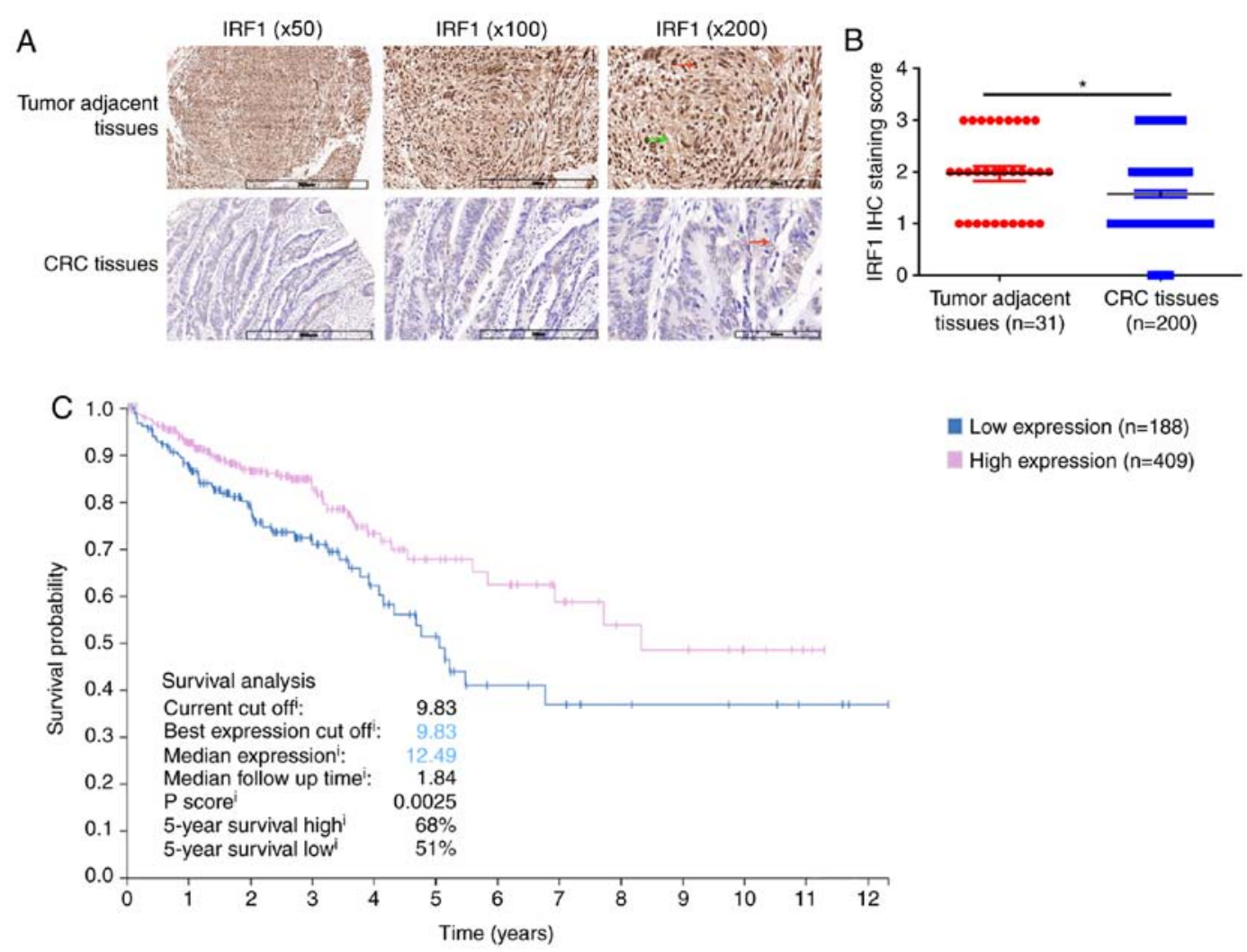

Low expression $(\mathrm{n}=188)$

High expression $(n=409)$

Figure 1. IRF1 expression in CRC tissues is significantly lower than that in adjacent tissues. (A) Representative images of the different staining patterns. Scale bar, 300, $20060 \mu \mathrm{m}$. Red arrows indicate the nucleus and green arrows indicate the cytoplasm. (B) IRF1 staining scores as assessed by IHC in CRC tumors $(\mathrm{n}=200)$ and adjacent tissues $(\mathrm{n}=31) .{ }^{*} \mathrm{P}<0.05$. (C) Association between IRF1 expression and the 5-year survival rate. Data were acquired from the Human Protein Atlas database. CRC, colorectal cancer; IHC, immunohistochemistry; IRF1, interferon regulatory factor 1.

A
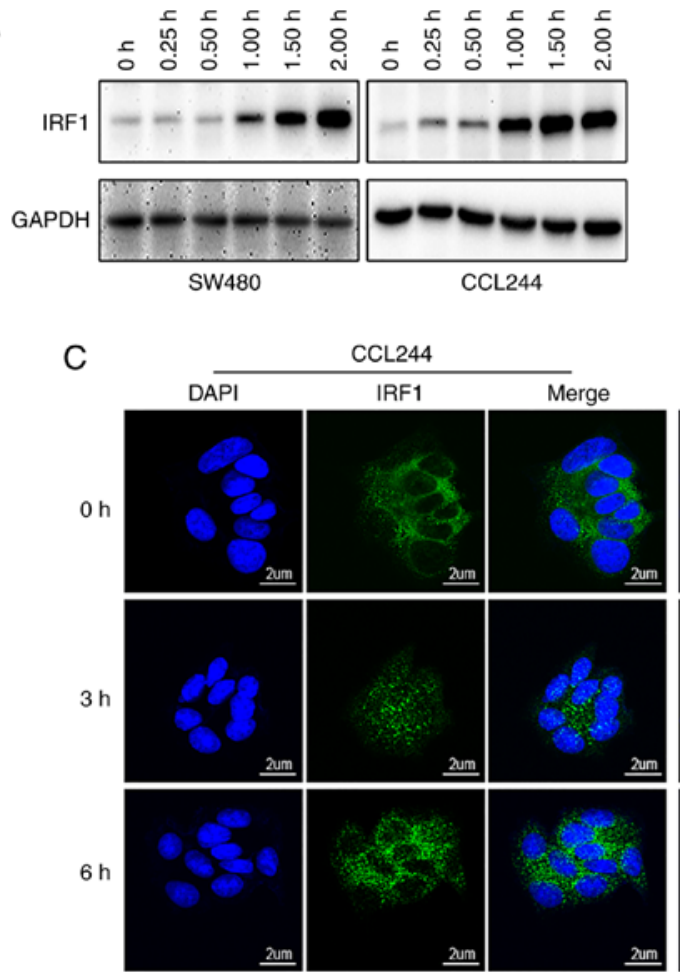

B
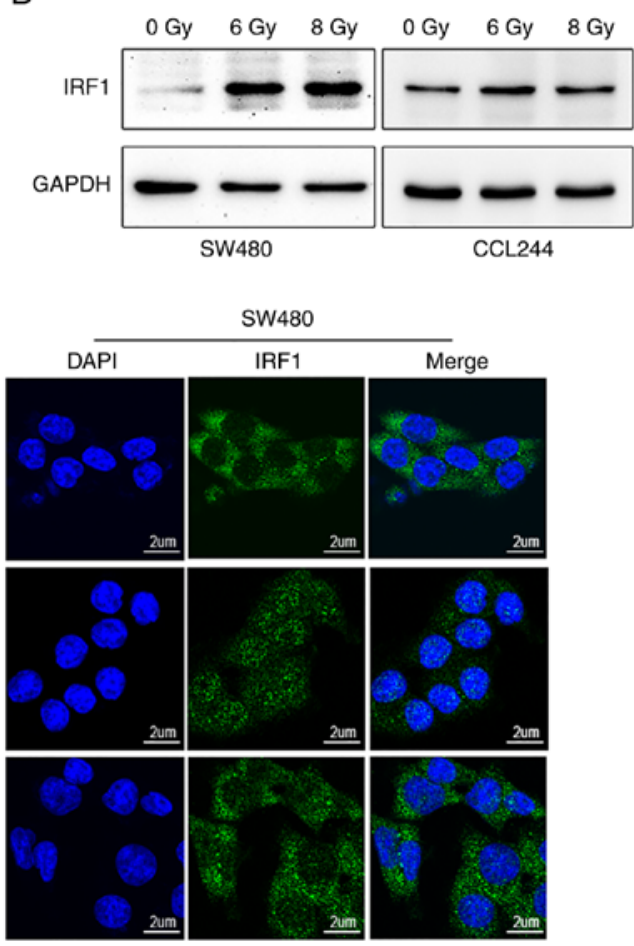

Figure 2. IRF1 expression in colorectal cancer cell lines is activated by IFN- $\gamma$ or X-rays. (A) IFN- $\gamma(10 \mathrm{ng} / \mathrm{ml})$ was added to a 6-well plate containing CCL244 and SW480 cells. Cells were harvested at $0.25,0.50,1.00,1.50$ and $2.00 \mathrm{~h}$ after IFN- $\gamma$ was added, proteins were extracted and the expression levels of IRF1 were detected by western blotting. (B) CCL244 and SW480 cells were treated with 0,6 and 8 Gy X-rays. After $48 \mathrm{~h}$, the cells were collected for protein extraction, and the expression levels of IRF1 were detected by western blotting. (C) X-ray irradiation of 0 and 6 Gy was administered to the two cell lines. The cells were fixed at 0,3 and $6 \mathrm{~h}$ after irradiation, and the distribution and expression of IRF1 in the cells were detected using immunofluorescence. Scale bar, $2 \mu \mathrm{m}$. IRF1, interferon regulatory factor 1 . 
A
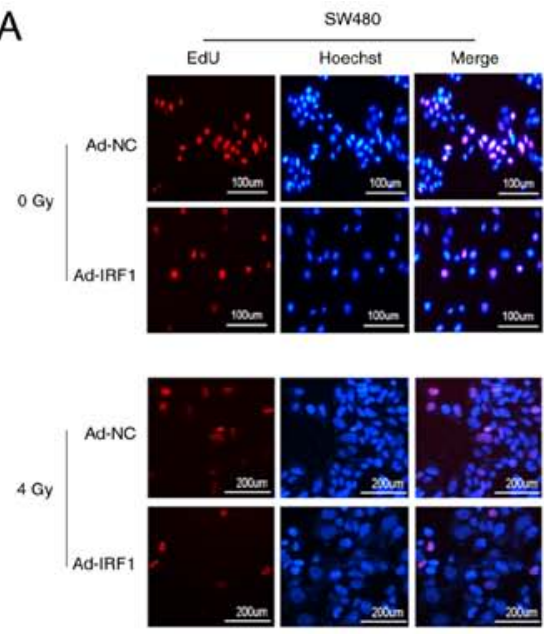

B

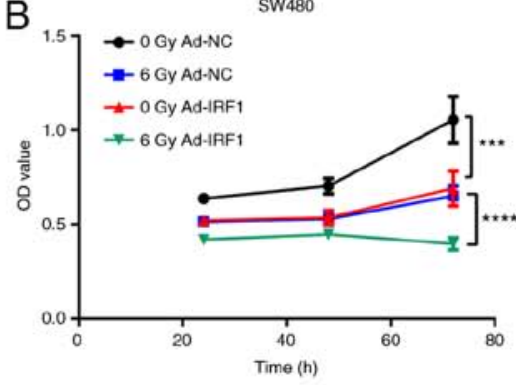

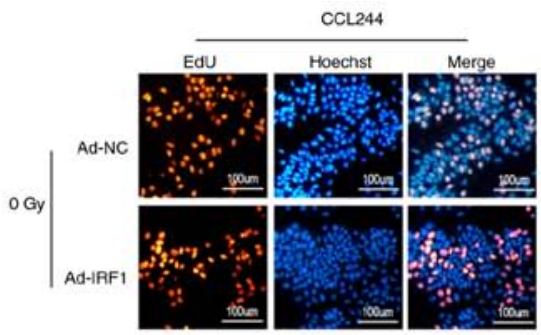
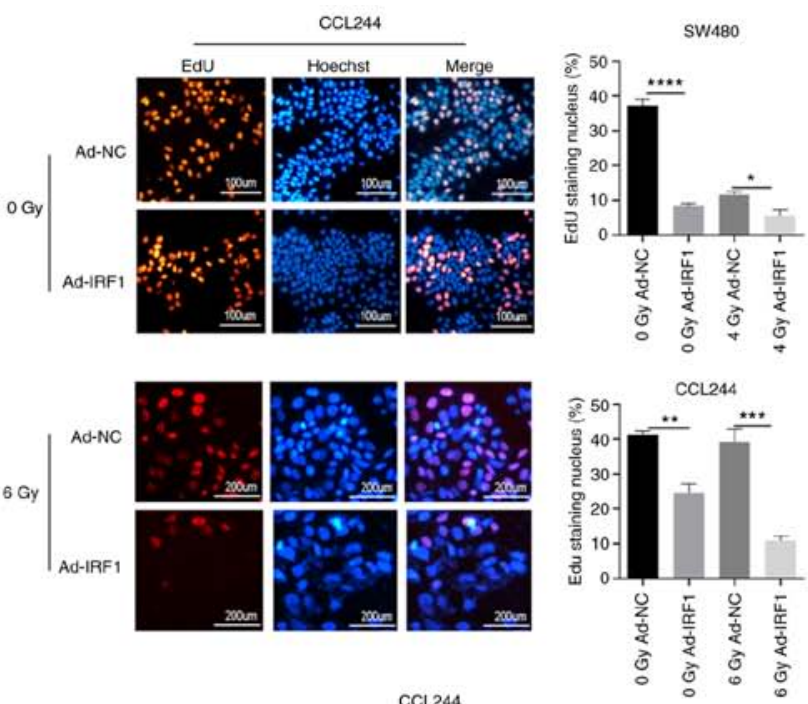

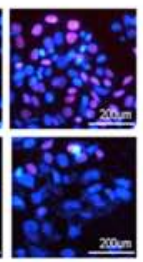

CCL244
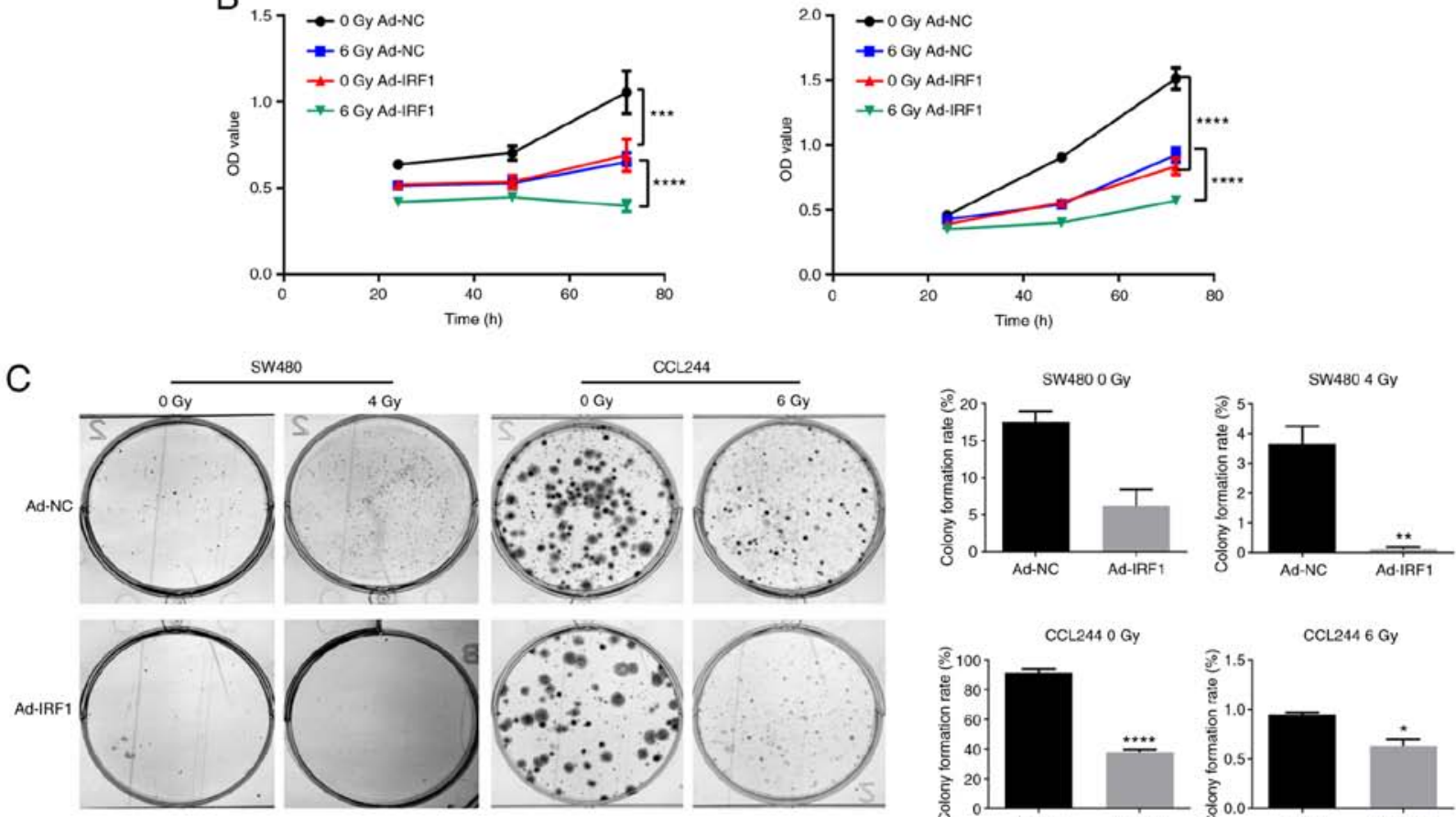

D
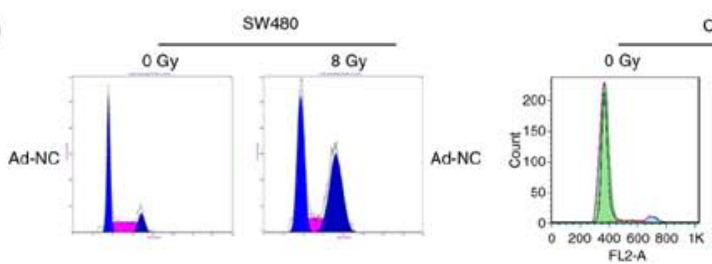

CCL244
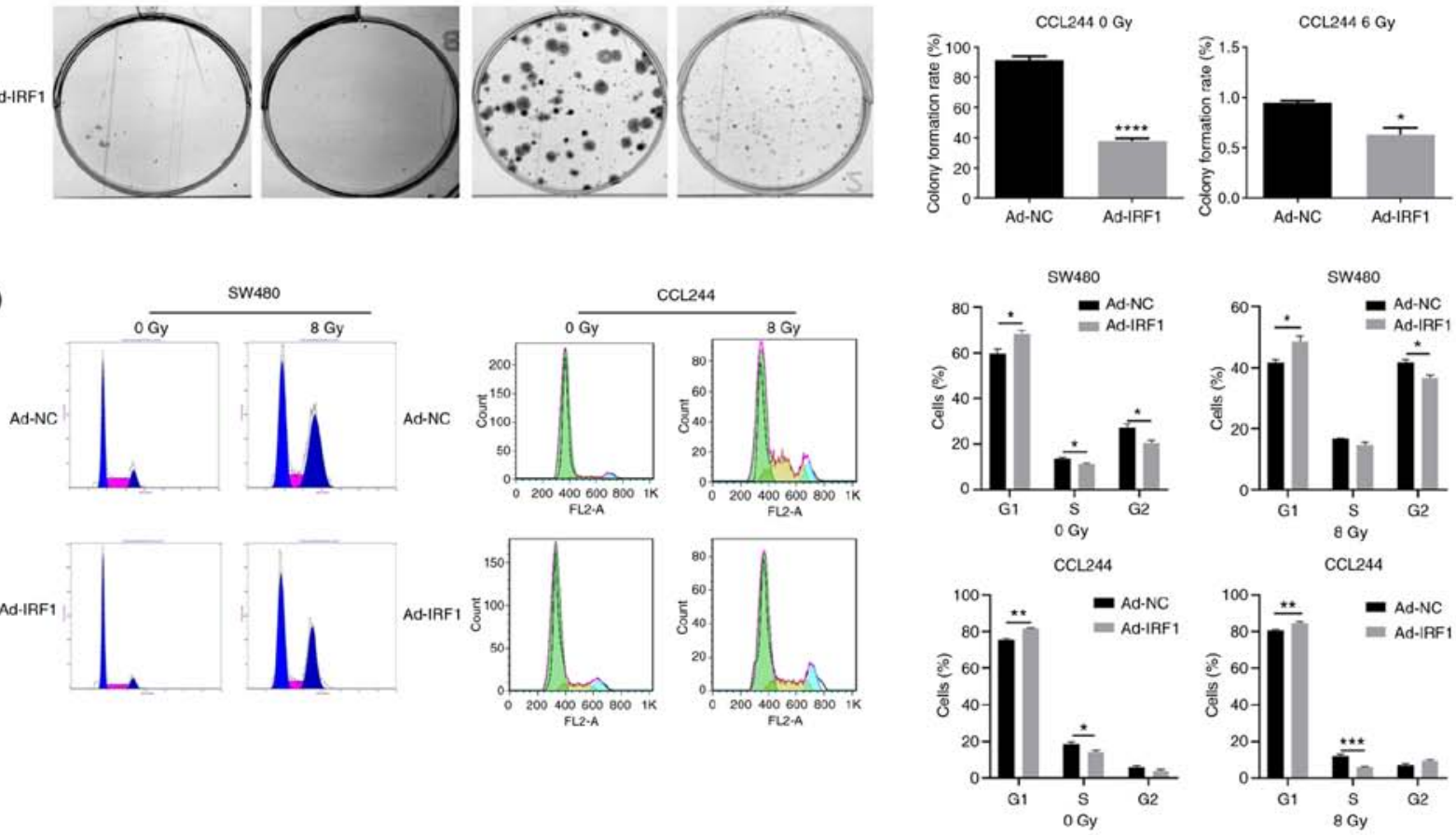

Figure 3. Overexpression of IRF1 inhibits the proliferation of CRC cells and increases their sensitivity to X-ray irradiation. (A) Subsequently, 0 and 4 or 6 Gy $\mathrm{X}$-rays were administered to the cells at $48 \mathrm{~h}$ after infection. At $48 \mathrm{~h}$ after irradiation, EdU was used to detect the proliferation of CRC cells. Scale bar, 100 or $200 \mu \mathrm{m}$. (B) Subsequently, 0 and $6 \mathrm{~Gy}$ X-rays were administered to the cells at $48 \mathrm{~h}$ after infection. At 24,48 and $72 \mathrm{~h}$ after irradiation, MTT was used to detect the proliferation of CRC cells. (C) After 14 days, the cells were fixed with pure methanol and then stained with Giemsa crystal violet, and the cell colony formation rate was calculated. (D) After $48 \mathrm{~h}$, a flow cytometer system was used to analyze the cell cycle ${ }^{*} \mathrm{P}<0.05,{ }^{* * *} \mathrm{P}<0.01,{ }^{* * * *} \mathrm{P}<0.001$ and ${ }^{* * * * *} \mathrm{P}<0.0001$. Ad, adenovirus expression vector; $\mathrm{CRC}$, colorectal cancer; EdU, 5-ethynyl-20-deoxyuridine; IRF1, interferon regulatory factor 1; NC, negative control; OD, optical density. 
A

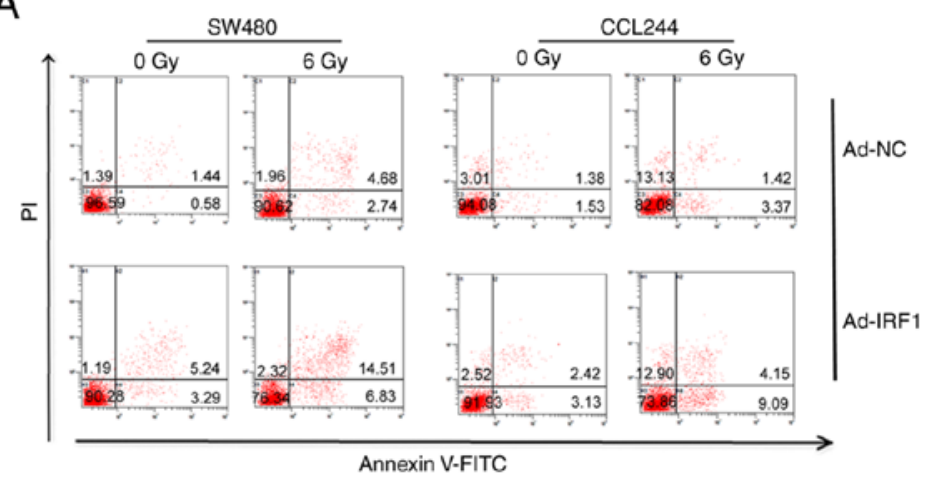

B

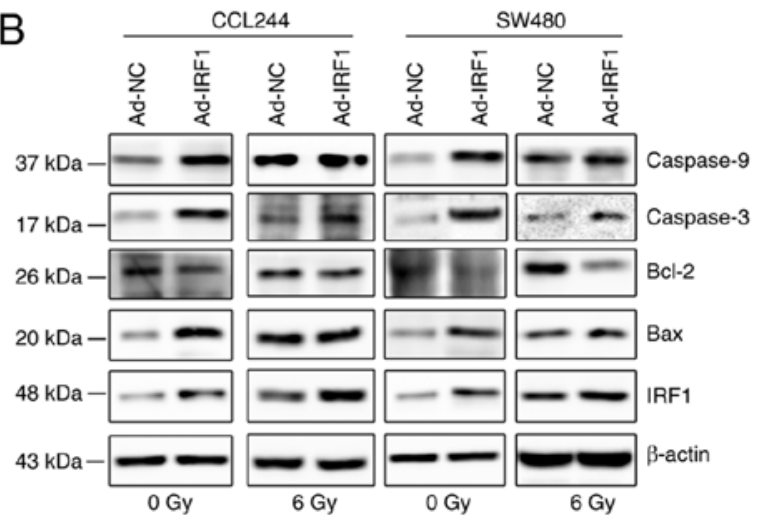

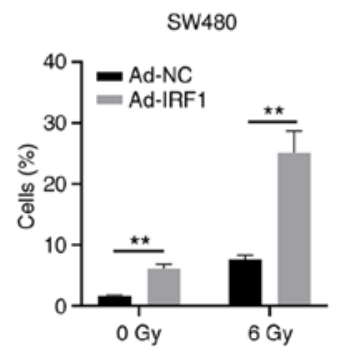

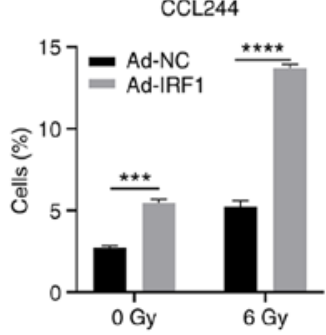

Figure 4. Overexpression of IRF1 increases X-ray-induced apoptosis. (A) At $48 \mathrm{~h}$ after infection, 0 and $6 \mathrm{~Gy}$ X-rays were administered to the cells. After $48 \mathrm{~h}$, a flow cytometer system was used to detect apoptosis of the cells. (B) At $48 \mathrm{~h}$ after infection, 0 and $6 \mathrm{~Gy} \mathrm{X}$-rays were administered to the cells. After $48 \mathrm{~h}$, the cells were harvested for protein isolation and western blotting to detect the expression levels of the apoptosis-related proteins Bax, Bcl-2, caspase-3 and caspase-9. ${ }^{* *} \mathrm{P}<0.01,{ }^{* * *} \mathrm{P}<0.001$ and ${ }^{* * * * *} \mathrm{P}<0.0001$. Ad, adenovirus expression vector; IRF1, interferon regulatory factor 1 ; NC, negative control.

western blot analysis (Fig. 2A). Notably, western blot analysis also revealed that IRF1 expression was induced by X-ray irradiation (Fig. 2B). Immunofluorescence analysis revealed that IRF1 expression in the nucleus was increased within $3 \mathrm{~h}$ after irradiation (Fig. 2C). In summary, IRF1 expression was induced by both IFN- $\gamma$ and X-ray treatment.

IRF1 enhances the effect of $X$-ray irradiation on the proliferation, apoptosis and cell cycle of CRC cells. EdU staining was performed to investigate the effect of IRF1 on the proliferation of CRC cells. Upregulation of IRF1 decreased the proliferation rate compared with the control before or after radiation (Fig. 3A). Cell proliferation was monitored using an MTT assay, and this revealed that IRF1 upregulation could inhibit the proliferation of SW480 and CCL244 before or after radiation (Fig. 3B). The colony formation assay demonstrated that the clonogenicity of CRC cells was significantly reduced after IRF1 upregulation before or after radiation (Fig. 3C). Furthermore, the cell cycle was analyzed using a fluorescence-activated cell sorter. The results revealed that the $G_{1}$ phase was significantly prolonged following upregulation of IRF1 (Fig. 3D). Overall, these results demonstrated that IRF1 upregulation inhibited proliferation, decreased colony formation efficiency and slowed the cell cycle.

Resistance to apoptosis is one of the most important radiation impairments occurring in tumors (34). To explore the effect of IRF1 on apoptosis induced by X-ray irradiation, flow cytometry analysis was performed. The results demonstrated that IRF1 upregulation significantly increased the apoptosis of cells with or without X-ray exposure. (Fig. 4A). Western blot analysis demonstrated that upregulation of IRF1 increased the expression levels of Bax, caspase-3 and caspase-9, and inhibited Bcl-2 expression (Fig. 4B). This further demonstrated that IRF1 may be involved in the regulation of CRC cell apoptosis.
IRF1 promotes radiosensitivity of $C R C$ to $X$-rays in vivo. To determine the effect of IRF1 on CRC growth in vivo, nude mice were inoculated with CCL244 cells that had been infected with Ad-NC or Ad-IRF1, or transfected with shRNA-NC or shRNA-IRF1 plasmids. Western blot analysis of IRF1 expression in CRC cells revealed that compared with the cells infected with Ad-NC, IRF1 expression in both SW480 and CCL244 cells infected with Ad-IRF1 was increased and compared with the cells transfected with shRNA-NC, IRF1 expression in both SW480 and CCL244 cells transfected with shRNA-IRF1 was reduced (Fig. S2). Nude mice inoculated with CCL244 cells infected with IRF1 overexpression adenovirus developed tumors slower than those in the control Ad-NC-infected group. By contrast, following IRF1 knockdown, the tumors grew much faster than those in other mouse groups (Fig. 5A). After the nude mice were sacrificed, tumor, liver and lung tissues were collected. The tumor volume was the smallest in the IRF1 upregulation group, and the tumor volume was the largest when IRF1 was downregulated (Fig. 5A). When observing the whole liver specimens, it was identified that the number of liver metastases was the lowest in the IRF1-upregulated group, while the number of metastases was the highest in the IRF1-downregulated group. For lung tissues, there were no nodules in the solid lung tissue observed by the naked eye. Therefore, no images were captured. When lung tissues were cut, there were isolated metastatic lung nodules in 1 mouse in the shRNA-IRF1 group (Fig. 5B and C). Further pathological tissue $H \& E$ staining revealed that the metastatic lesions in the IRF1-downregulated group were the largest, while the lesions in the IRF1-upregulated group were not obvious. In addition, pathological H\&E staining of the lung revealed no metastases in the IRF1-upregulated group and obvious metastases in the IRF1-downregulated group (Fig. 5D). Tumor tissues and liver 

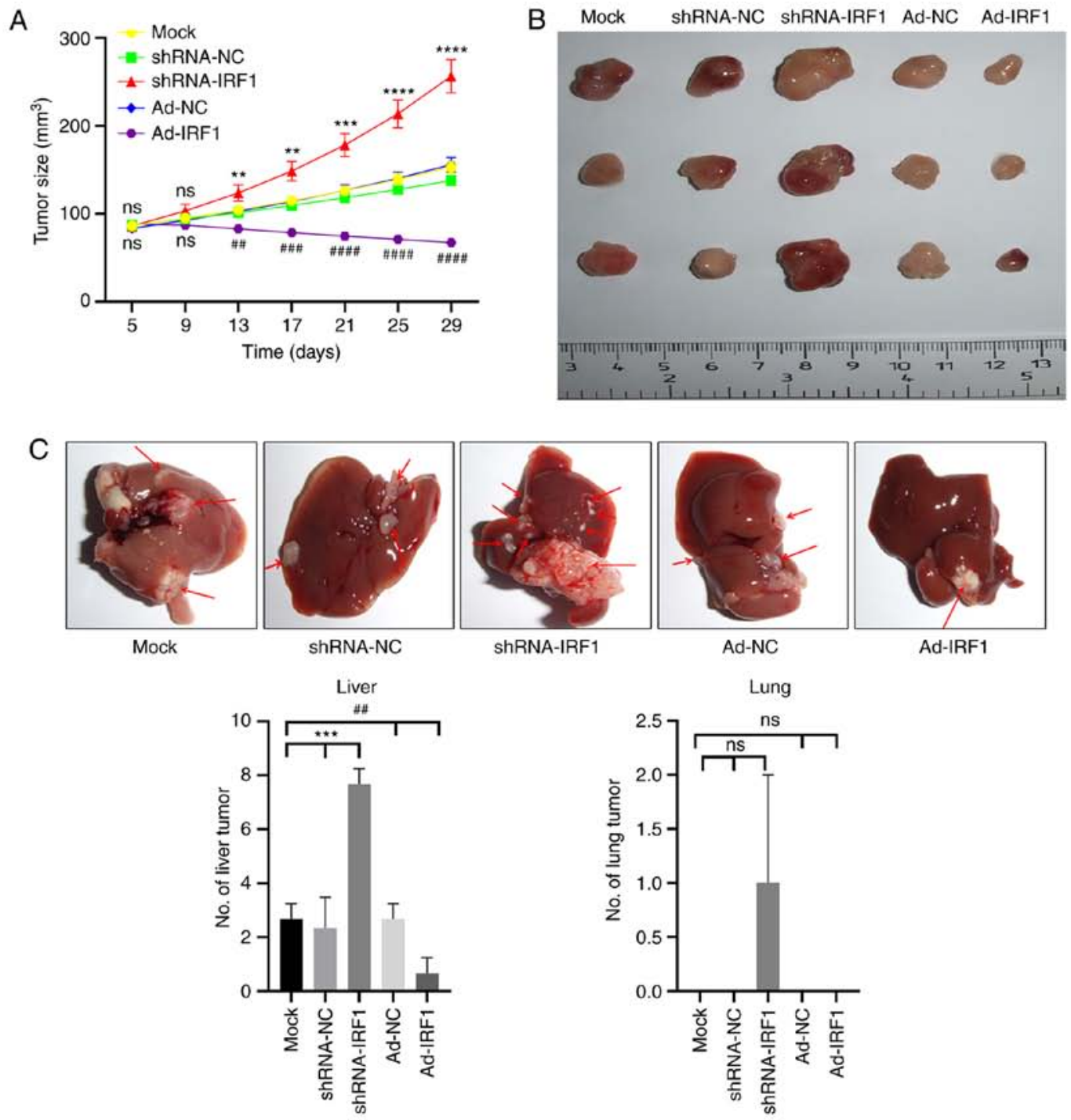

D

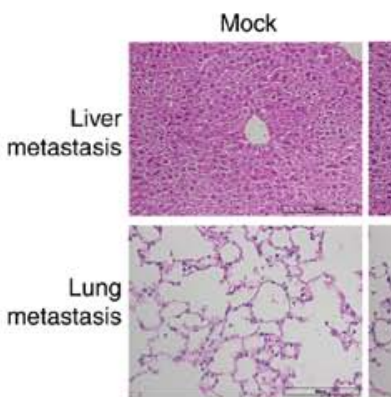

ShRNA-NC
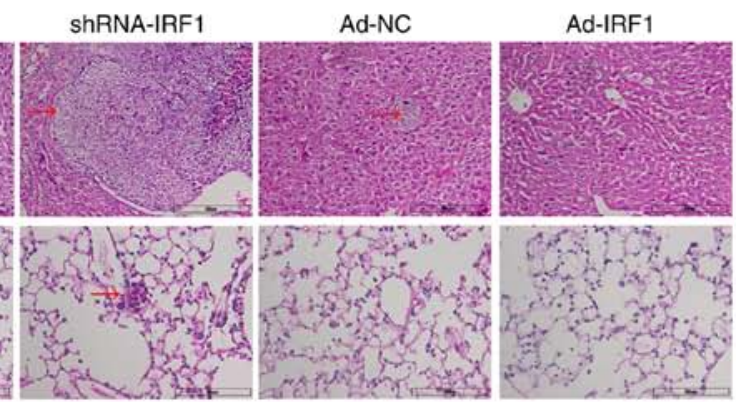

$\mathrm{E}$

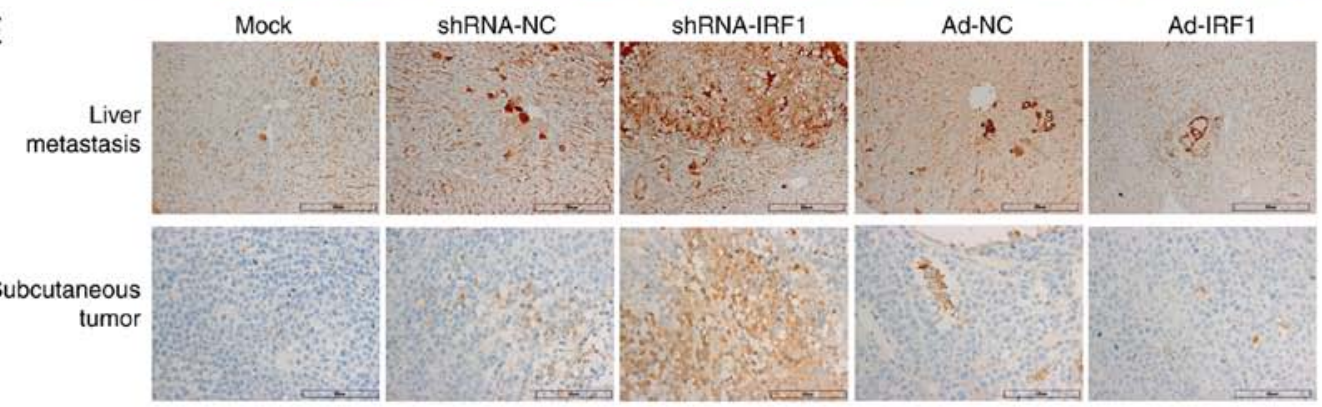

Figure 5. Overexpression of IRF1 promotes radiosensitivity of CRC to X-rays in vivo. (A) Tumor growth curve of each group. (B) Representative tumors from each group of mice. (C) Representative CRC metastases in the liver. Red arrows indicate lesions. Analysis of the number of liver and lung metastases in each group. (D) H\&E staining of nodules in the liver and lung for CRC metastasis for each group. Red arrows indicate lesions. Scale bar, $60 \mu \mathrm{m}$. (E) Immunohistochemical detection of Bcl-2 expression in liver metastases and subcutaneous tumors for each group. Scale bar, $60 \mu \mathrm{m}$. ${ }^{* *} \mathrm{P}<0.01,{ }^{* * * *} \mathrm{P}<0.001$ and ${ }^{* * * *} \mathrm{P}<0.0001$ (shRNA-IRF1 vs. shRNA-NC/mock); ${ }^{\# \#} \mathrm{P}<0.01$, ${ }^{\# \# \#} \mathrm{P}<0.001$ and ${ }^{\# \# \# "} \mathrm{P}<0.0001$ (Ad-IRF1 vs. Ad-NC/mock). Ad, adenovirus expression vector; CRC, colorectal cancer; IRF1, interferon regulatory factor 1; NC, negative control; ns, not significant; shRNA, short hairpin RNA. 
Table I. Significantly upregulated mRNAs following the overexpression of IRF1 according to RNA sequencing.

\begin{tabular}{|c|c|c|c|c|c|c|c|c|}
\hline ID & Base mean & $\begin{array}{c}\text { Base mean } \\
\text { control } \\
\text { sample NC }\end{array}$ & $\begin{array}{c}\text { Base mean } \\
\text { case sample } \\
\text { Ad-IRF1 }\end{array}$ & Fold change & $\begin{array}{l}\log _{2} \text { fold } \\
\text { change }\end{array}$ & P-value & $\begin{array}{l}\text { Adjusted } \\
\text { P-value }\end{array}$ & Gene \\
\hline IFI6 & 8362.5161 & 2804.2397 & 13920.7926 & 4.9642 & 2.3116 & 0 & 0 & Up \\
\hline BST2 & 131.2432 & 23.2430 & 239.2434 & 10.2931 & 3.3636 & $1.65 \times 10^{-53}$ & $1.30 \times 10^{-49}$ & Up \\
\hline TFF1 & 773.5291 & 480.7576 & 1066.3006 & 2.2180 & 1.1492 & $1.21 \times 10^{-33}$ & $1.46 \times 10^{-30}$ & Up \\
\hline ISG15 & 6329.8561 & 3499.2967 & 9160.4154 & 2.6178 & 1.3883 & $2.49 \times 10^{-33}$ & $2.79 \times 10^{-30}$ & Up \\
\hline TMEM238 & 432.1279 & 251.8244 & 612.4313 & 2.4320 & 1.2821 & $3.19 \times 10^{-30}$ & $3.13 \times 10^{-27}$ & Up \\
\hline RARRES3 & 247.1411 & 136.0866 & 358.1957 & 2.6321 & 1.3962 & $4.76 \times 10^{-23}$ & $2.49 \times 10^{-20}$ & Up \\
\hline LRRC26 & 240.0970 & 139.0721 & 341.1219 & 2.4528 & 1.2945 & $1.11 \times 10^{-19}$ & $3.49 \times 10^{-17}$ & $\mathrm{Up}$ \\
\hline NUPR1 & 192.9297 & 105.5262 & 280.3331 & 2.6565 & 1.4095 & $5.60 \times 10^{-19}$ & $1.60 \times 10^{-16}$ & Up \\
\hline IFITM1 & 180.7444 & 76.9545 & 284.5344 & 3.6974 & 1.8865 & $9.90 \times 10^{-18}$ & $2.35 \times 10^{-15}$ & Up \\
\hline C4orf48 & 1337.1611 & 856.0667 & 1818.2556 & 2.1240 & 1.0868 & $1.55 \times 10^{-16}$ & $2.94 \times 10^{-14}$ & Up \\
\hline IFI35 & 245.9523 & 159.7153 & 332.1892 & 2.0799 & 1.0565 & $4.29 \times 10^{-14}$ & $5.26 \times 10^{-12}$ & Up \\
\hline SPINK4 & 609.8811 & 393.3366 & 826.4257 & 2.1011 & 1.0711 & $6.25 \times 10^{-13}$ & $5.89 \times 10^{-11}$ & $\mathrm{Up}$ \\
\hline CBR3 & 210.2773 & 138.8154 & 281.7391 & 2.0296 & 1.0212 & $7.98 \times 10^{-12}$ & $5.91 \times 10^{-10}$ & Up \\
\hline GADD45G & 154.6964 & 90.6289 & 218.7639 & 2.4138 & 1.2713 & $2.96 \times 10^{-11}$ & $1.94 \times 10^{-9}$ & Up \\
\hline MRPL23 & 4537.9171 & 3004.8832 & 6070.9510 & 2.0204 & 1.0146 & $6.21 \times 10^{-11}$ & $3.68 \times 10^{-9}$ & Up \\
\hline MYH4 & 32.3621 & 10.9477 & 53.7765 & 4.9121 & 2.2964 & $4.95 \times 10^{-9}$ & $1.73 \times 10^{-7}$ & Up \\
\hline SMIM22 & 619.3599 & 411.7948 & 826.9250 & 2.0081 & 1.0058 & $6.72 \times 10^{-9}$ & $2.28 \times 10^{-7}$ & Up \\
\hline LGALS9 & 34.6546 & 12.7458 & 56.5634 & 4.4378 & 2.1498 & $1.10 \times 10^{-8}$ & $3.55 \times 10^{-7}$ & Up \\
\hline TSTA3 & 174.7754 & 109.1525 & 240.3983 & 2.2024 & 1.1391 & $7.56 \times 10^{-8}$ & $1.96 \times 10^{-6}$ & Up \\
\hline SHD & 34.9248 & 14.7999 & 55.0497 & 3.7196 & 1.8951 & $2.99 \times 10^{-7}$ & $6.68 \times 10^{-6}$ & Up \\
\hline
\end{tabular}

Ad, adenovirus expression vector; IRF1, interferon regulatory factor 1; NC, negative control.

metastases were prepared for immunohistochemical staining. The results revealed that $\mathrm{Bcl}-2$ protein expression in tumor tissues and liver metastases of the Ad-IRF1 group was lower than that in the Ad-NC group, while Bcl-2 expression in the IRF1 downregulation group was the highest (Fig. 5E). These results were consistent with the results of the present in vitro experiments. In summary, the present results demonstrated that IRF1 regulation affected tumor growth, metastasis and apoptosis-related protein Bcl-2 expression in vivo.

IRF1 affects the biological behavior of CRC, likely by regulating the expression levels of interferon-induced proteins. To further explore the effect of IRF1 on the biological behavior of CRC, the present study examined the expression levels of mRNAs after IRF1 upregulation by RNA sequencing. Based on the sequencing results, the present study identified 20 mRNAs that were upregulated or downregulated, and a heat map was generated (Fig. 6A). Detailed information is included in Tables I and II. The present study identified that among the upregulated mRNAs, the expression levels of three interferon-induced proteins (IFI6, IFITM1 and IFI35) were increased significantly. Their expression was positively associated with IRF1, as demonstrated by western blot analysis (Fig. 6B).

Gene Ontology analysis, based on RNA sequencing results, indicated that IRF1 could upregulate numerous genes that are involved in the 'type I interferon signaling pathway', 'response to interferon-beta', 'innate immune response in mucosa' and 'response to interferon-gamma', suggesting that
IRF1 participates in interferon-regulated tumor immunity, as aforementioned. The signaling pathway analysis also indicated that IRF1 was involved in the regulation of multiple cellular components of CRC cells, especially the cellular membrane structure, such as 'nucleosome', 'nuclear nucleosome', 'lipid particle', 'apical plasma membrane' and 'extracellular exosome'. Furthermore, IRF1 was demonstrated to affect cellular activity at molecular levels, such as 'insulin-like growth factor binding', 'phospholipase A2 activity' and 'protein heterodimerization activity' in CRC cells, which may be achieved by regulating membrane structure (Fig. 6C).

\section{Discussion}

The roles IRF1 serves in innate and adaptive tumor immunity have become a popular research topic in recent years. The effects of IRF1 on antitumor immunity depend on affecting mitochondrial dynamics (35) and glycolysis (36), regulating programmed death-ligand 1 (PD-L1) (37-40) and even priming tumor-derived exosomes (41). Lai et al (42) reported that decitabine improves the efficiency of anti-programmed cell death protein-1 (PD-1) therapy for lung cancer by activating the hypomethylation of IRF1/7 in the IFN response signaling pathway. Wu et al (43) revealed that YAP inhibits IFNc-inducible PD-L1 expression partially through microRNA-130a-mediated suppression of vestigial like family member 4 and IRF1 expression, thereby reducing the PD-L1 interaction with PD-1 to escape T-cell immune surveillance 
Table II. Significantly downregulated mRNAs following the overexpression of IRF1 according to RNA sequencing.

\begin{tabular}{|c|c|c|c|c|c|c|c|c|}
\hline ID & Base mean & $\begin{array}{c}\text { Base mean } \\
\text { control sample } \\
\text { NC }\end{array}$ & $\begin{array}{c}\text { Base mean } \\
\text { case sample } \\
\text { Ad-IRF1 }\end{array}$ & Fold change & $\begin{array}{l}\log _{2} \text { fold } \\
\text { change }\end{array}$ & $\mathrm{P}$-value & $\begin{array}{l}\text { Adjusted } \\
\text { P-value }\end{array}$ & Gene \\
\hline CYR61 & 286.7657 & 445.3502 & 128.1812 & 0.2878 & -1.7968 & $5.70 \times 10^{-39}$ & $1.79 \times 10^{-35}$ & Down \\
\hline CTGF & 226.0636 & 362.1031 & 90.0241 & 0.2486 & -2.0080 & $1.09 \times 10^{-38}$ & $2.86 \times 10^{-35}$ & Down \\
\hline SLC2A3 & 411.6516 & 618.3295 & 204.9737 & 0.3315 & -1.5929 & $1.27 \times 10^{-37}$ & $2.74 \times 10^{-34}$ & Down \\
\hline GPRC5A & 861.9170 & 1180.5053 & 543.3287 & 0.4603 & -1.1195 & $1.39 \times 10^{-37}$ & $2.74 \times 10^{-34}$ & Down \\
\hline C1orf116 & 432.2862 & 629.9506 & 234.6219 & 0.3724 & -1.4249 & $3.39 \times 10^{-36}$ & $5.92 \times 10^{-33}$ & Down \\
\hline TINAGL1 & 717.7809 & 986.1473 & 449.4144 & 0.4557 & -1.1338 & $3.75 \times 10^{-34}$ & $5.35 \times 10^{-31}$ & Down \\
\hline AMOTL2 & 449.3289 & 700.5839 & 198.0739 & 0.2827 & -1.8225 & $2.93 \times 10^{-29}$ & $2.70 \times 10^{-26}$ & Down \\
\hline KRT4 & 454.6213 & 609.3405 & 299.9020 & 0.4922 & -1.0228 & $8.74 \times 10^{-21}$ & $3.35 \times 10^{-18}$ & Down \\
\hline ANKRD1 & 44.2735 & 81.4814 & 7.0655 & 0.0867 & -3.5276 & $3.36 \times 10^{-20}$ & $1.15 \times 10^{-17}$ & Down \\
\hline AJUBA & 657.5500 & 909.5501 & 405.5498 & 0.4459 & -1.1653 & $1.63 \times 10^{-19}$ & $5.03 \times 10^{-17}$ & Down \\
\hline CLIC5 & 348.2467 & 471.4531 & 225.0403 & 0.4773 & -1.0669 & $2.02 \times 10^{-18}$ & $5.38 \times 10^{-16}$ & Down \\
\hline SAMD4A & 146.1898 & 214.0379 & 78.3416 & 0.3660 & -1.4500 & $1.41 \times 10^{-15}$ & $2.27 \times 10^{-13}$ & Down \\
\hline TAF13 & 106.3080 & 155.0966 & 57.5194 & 0.3709 & -1.4310 & $9.57 \times 10^{-12}$ & $6.90 \times 10^{-10}$ & Down \\
\hline ZNF566 & 209.2546 & 290.5804 & 127.9288 & 0.4403 & -1.1836 & $1.15 \times 10^{-11}$ & $8.20 \times 10^{-10}$ & Down \\
\hline CITED2 & 192.1906 & 259.8504 & 124.5308 & 0.4792 & -1.0612 & $1.96 \times 10^{-11}$ & $1.35 \times 10^{-9}$ & Down \\
\hline EMP1 & 303.1375 & 421.9202 & 184.3549 & 0.4369 & -1.1945 & $2.02 \times 10^{-11}$ & $1.38 \times 10^{-9}$ & Down \\
\hline GALNT3 & 306.3284 & 426.9941 & 185.6626 & 0.4348 & -1.2015 & $4.12 \times 10^{-11}$ & $2.55 \times 10^{-9}$ & Down \\
\hline PAQR3 & 161.8251 & 220.2059 & 103.4443 & 0.4698 & -1.0900 & $1.47 \times 10^{-10}$ & $8.01 \times 10^{-9}$ & Down \\
\hline ZNF540 & 118.3167 & 167.1335 & 69.4998 & 0.4158 & -1.2659 & $1.80 \times 10^{-10}$ & $9.46 \times 10^{-9}$ & Down \\
\hline GRHL3 & 87.9749 & 134.5827 & 41.3672 & 0.3074 & -1.7019 & $4.25 \times 10^{-10}$ & $2.05 \times 10^{-8}$ & Down \\
\hline
\end{tabular}

Ad, adenovirus expression vector; IRF1, interferon regulatory factor 1; NC, negative control.

and reduce the immunotherapeutic effect on tumors. In fact, the role of IRF1 itself is not limited to immunotherapy; it serves a decisive role in tumor growth, invasion and migration, and tumor radiotherapy and chemotherapy.

IRF1 also serves an important role in the tumor response to radiation. As early as 2009 , a study reported that IRF1 is an important radiation-specific biomarker of cancers, as analyzed by microarray and bioinformatics analyses (44). It has been reported that IRF1 is mainly localized in the cytoplasm and translocates to the nucleus after activation (20). Similar to the previous research results, the present study revealed that when CRC cells were treated with X-rays, the distribution of IRF1 in the cytoplasm and nucleus was altered, and the total protein expression levels of IRF1 were increased for different radiation doses and irradiation time points.

It is now clear that IRF1 has anti-oncogenic activity by blocking cell cycle progression, inducing tumor suppressor genes, downregulating growth-promoting genes and upregulating the apoptosis process $(6,45)$. The present study revealed that when IRF1 was upregulated, the proliferation rate of CRC cells was decreased, and the tumor size was smaller than that of the control. The percentage of cells undergoing apoptosis was increased, and the cell cycle was blocked. Furthermore, all inhibitory effects of X-ray radiation on CRC were aggravated. Previous studies have demonstrated that IRF1 affects the migration and invasion of tumor cells (46-48). Jiang et al (49) reported that downregulation of IRF1 could increase the invasion capacity and abrogate the inhibitory effect of myotubularin related protein 2 knockdown on the invasion of gastric cancer cells. These findings are consistent with the present results in CRC, revealing that upregulation of IRF1 inhibited distant metastasis of CRC to the liver and lung in vivo.

The present results demonstrated that IRF1 regulated the expression levels of interferon-induced proteins (IFI6, IFITM1 and IFI35), as analyzed by RNA sequencing and western blotting. These three interferon-induced proteins are mostly involved in immune responses caused by viral infection (50-52). Their involvement in the development of cancer is also evident. Studies have identified that both IFI6 (53) and IFITM1 (54) are involved in the development of breast cancer, while IFI35 is involved in the regulation of the innate immune response of astrocytoma (55). Furthermore, these three proteins are known to have a close association with IRF1. A previous study reported that both IRF1 and IFI6 are positively associated with the drug-specific chemosensitivity of gastric cancer (56). Gómez-Herranz et al (57) revealed that IRF1 is one of the most dominant IFN- $\gamma$ inducible proteins whose synthesis is attenuated in IFITM1/IFITM3-negative cervical cancer cells. Yang et al (58) reported that IRF1 could directly bind to one site of the IFI35 promoter and mediate IFN- $\gamma$-dependent transcriptional activation of IFI35 in HeLa cells. These findings support the hypothesis that IRF1 affects the biological behavior of CRC by regulating interferon-induced proteins. Based on the present results and the literature, it was hypothesized that IRF1 may affect the development and radiosensitivity of CRC through interferon-induced proteins. This hypothesis merits further investigation. 

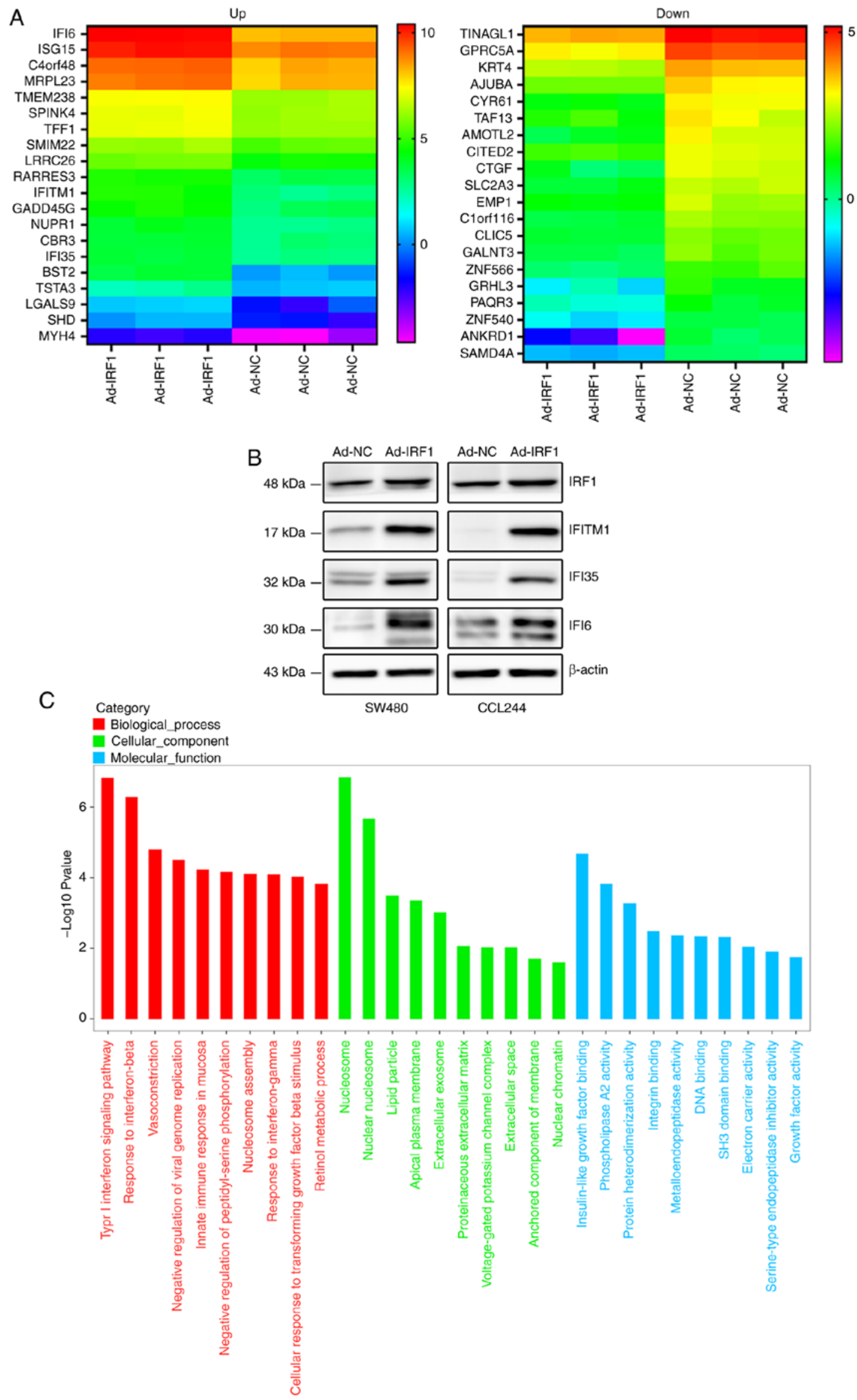

Figure 6. Overexpression of IRF1 promotes the expression of interferon-induced proteins. (A) Heat map of the significant mRNA expression patterns in the Ad-IRF1 and Ad-NC groups. (B) Western blotting supported the RNA sequencing results. (C) Gene Ontology biological process, cellular component and molecular function analysis. Ad, adenovirus expression vector; IFI6, interferon $\alpha$ inducible protein 6; IFI35, interferon induced protein 35; IFITM1, interferon induced transmembrane protein 1 ; IRF1, interferon regulatory factor 1 ; NC, negative control. 
In summary, the present study demonstrated that IRF1 expression was downregulated in CRC tissues and that it was positively associated with patient prognosis. IRF1 upregulation inhibited the progression and increased the radiosensitivity of CRC likely by regulating the expression levels of interferon-induced proteins.

\section{Acknowledgements}

Not applicable.

\section{Funding}

The present study was supported by the National Natural Science Foundation of China (grant no. 81703022), Jiangsu Province Key Youth Talents Project (grant no. QNRC2016262), Gusu Health Talents Training Project (grant no.GSWS2019078) and Jiangsu Province Graduate Research and Practice Innovation Project (grant no. KYCX17_1995). The funders had no role in study design, data collection and analysis, decision to publish, or preparation of the manuscript.

\section{Availability of data and materials}

The datasets used and/or analyzed during the current study are available from the corresponding author on reasonable request.

\section{Authors' contributions}

$\mathrm{XX}, \mathrm{KY}$ and YW conceived and coordinated the study, designed, performed and analyzed the experiments, and drafted the manuscript. YH, WD and CX carried out the data collection and analysis and revised the manuscript. The authenticity of the raw data was assessed by XX and CX. All authors read and approved the final manuscript.

\section{Ethics approval and consent to participate}

All patients provided signed, informed consent for their tissues to be used for scientific research. Ethical approval for the study was obtained from the Second Hospital of Wuxi (approval no. KY-2020-001; Wuxi, China). The present study was approved by the Institutional Animal Care and Use Committee of Soochow University (Suzhou, China).

\section{Patient consent for publication}

Not applicable.

\section{Competing interests}

The authors declare that they have no competing interests.

\section{References}

1. González-Quezada BA, Santana-Bejarano UF, Corona-Rivera A, Pimentel-Gutiérrez HJ, Silva-Cruz R, Ortega-De-la-Torre C, Franco-Topete R, Franco-Topete K, Centeno-Flores MW, Maciel-Gutiérrez VM, et al: Expression profile of NF- $\mathrm{NB}$ regulated genes in sporadic colorectal cancer patients. Oncol Lett 15: 7344-7354, 2018.
2. Siegel RL, Miller KD and Jemal A: Cancer statistics, 2019. CA Cancer J Clin 69: 7-34, 2019.

3. Chiu HM, Hsu WF, Chang LC and Wu MH: Colorectal cancer screening in Asia. Curr Gastroenterol Rep 19: 47, 2017.

4. Abraha I, Aristei C, Palumbo I, Lupattelli M, Trastulli S, Cirocchi R, De Florio R and Valentini V: Preoperative radiotherapy and curative surgery for the management of localised rectal carcinoma. Cochrane Database Syst Rev 10: Cd002102, 2018.

5. Liu N, Cui W, Jiang X,Zhang Z, Gnosa S, Ali Z, Jensen L, Jönsson JI, Blockhuys S, Lam EWF, et al: The critical role of dysregulated RhoB signaling pathway in radioresistance of colorectal cancer. Int J Radiat Oncol Biol Phys 104: 1153-1164, 2019.

6. Alsamman K and El-Masry OS: Interferon regulatory factor 1 inactivation in human cancer. Biosci Rep 38: BSR20171672, 2018.

7. Campos Carrascosa L, Klein M, Kitagawa Y, Lückel C, Marini F, König A, Guralnik A, Raifer H, Hagner-Benes S, Rädler D, et al: Reciprocal regulation of the I19 locus by counteracting activities of transcription factors IRF1 and IRF4. Nat Commun 8: 15366, 2017.

8. Carrascosa LC, Klein M, Kitagawa Y, Lückel C, Marini F, König A, Guralnik A, Raifer H, Hagner-Benes S, Rädler D, et al: Reciprocal regulation of the I19 locus by counteracting activities of transcription factors IRF1 and IRF4. Nat Commun 8: 15366, 2017.

9. Ramsauer K, Farlik M, Zupkovitz G, Seiser C, Kröger A, Hauser $\mathrm{H}$ and Decker T: Distinct modes of action applied by transcription factors STAT1 and IRF1 to initiate transcription of the IFN-gamma-inducible gbp2 gene. Proc Natl Acad Sci USA 104: 2849-2854, 2007.

10. Cook KL, Schwartz-Roberts JL, Baumann WT and Clarke R: Linking autophagy with inflammation through IRF1 signaling in ER+ breast cancer. Mol Cell Oncol 3: e1023928, 2015

11. Walch-Ruckheim B, Pahne-Zeppenfeld J, Fischbach J, Wickenhauser C, Horn LC, Tharun L, Büttner R, Mallmann P, Stern P, Kim YJ, et al: STAT3/IRF1 pathway activation sensitizes cervical cancer cells to chemotherapeutic drugs. Cancer Res 76: 3872-3883, 2016.

12. Mao L, Zhang Y, Mo W, Yu Y and Lu H: BANF1 is downregulated by IRF1-regulated microRNA-203 in cervical cancer. PLoS One 10: e0117035, 2015.

13. Yu M, Xue H, Wang Y, Shen Q, Jiang Q, Zhang X, Li K, Jia M, Jia J, Xu J and Tian Y: miR-345 inhibits tumor metastasis and EMT by targeting IRF1-mediated mTOR/STAT3/AKT pathway in hepatocellular carcinoma. Int J Oncol 50: 975-983, 2017.

14. Ebine K, Kumar K, Pham TN, Shields MA, Collier KA, Shang M, DeCant BT, Urrutia R, Hwang RF, Grimaldo S, et al: Interplay between interferon regulatory factor 1 and BRD4 in the regulation of PD-L1 in pancreatic stellate cells. Sci Rep 8: 13225, 2018.

15. Kanayama M, Hayano T, Koebis M, Maeda T, Tabe Y, Horie S and Aiba A: Hyperactive mTOR induces neuroendocrine differentiation in prostate cancer cell with concurrent up-regulation of IRF1. Prostate 77: 1489-1498, 2017.

16. Bachmann SB, Frommel SC, Camicia R, Winkler HC, Santoro R and Hassa PO: DTX3L and ARTD9 inhibit IRF1 expression and mediate in cooperation with ARTD8 survival and proliferation of metastatic prostate cancer cells. Mol Cancer 13: 125, 2014.

17. Yuan L, Zhou C, Lu Y, Hong M, Zhang Z, Zhang Z, Chang Y, Zhang C and Li X: IFN- $\gamma$-mediated IRF1/miR-29b feedback loop suppresses colorectal cancer cell growth and metastasis by repressing IGF1. Cancer Lett 359: 136-147, 2015.

18. Hong M, Zhang Z, Chen Q, Lu Y, Zhang J, Lin C, Zhang F, Zhang W, Li X, Zhang W and Li X: IRF1 inhibits the proliferation and metastasis of colorectal cancer by suppressing the RAS-RAC1 pathway. Cancer Manag Res 11: 369-378, 2019.

19. Chen X, Liu L, Mims J, Punska EC, Williams KE, Zhao W, Arcaro KF, Tsang AW, Zhou X and Furdui CM: Analysis of DNA methylation and gene expression in radiation-resistant head and neck tumors. Epigenetics 10: 545-561, 2015.

20. Chen J, Markelc B, Kaeppler J, Ogundipe VML, Cao Y, McKenna WG and Muschel RJ: STING-dependent interferon- $\lambda 1$ induction in HT29 cells, a human colorectal cancer cell line, after gamma-radiation. Int J Radiat Oncol Biol Phys 101: 97-106, 2018 .

21. Gonzalez RS, Raza A, Propst R, Adeyi O, Bateman J, Sopha SC, Shaw $J$ and Auerbach A: Recent advances in digestive tract tumors: Updates from the 5th edition of the world health organization 'Blue Book'. Arch Pathol Lab Med: Jul 31, 2020 (Epub ahead of print). doi: 10.5858/arpa.2020-0047-RA. 
22. Xu X, Song C, Chen Z, Yu C, Wang Y, Tang Y and Luo J: Downregulation of HuR inhibits the progression of esophageal cancer through interleukin-18. Cancer Res Treat 50: 71-87, 2018.

23. Thul PJ and Lindskog C: The human protein atlas: A spatial map of the human proteome. Protein Sci 27: 233-244, 2018.

24. Yang XD, Xu XH, Zhang SY, Wu Y, Xing CG, Ru G, Xu HT and Cao JP: Role of miR-100 in the radioresistance of colorectal cancer cells. Am J Cancer Res 5: 545-559, 2015.

25. Kim D, Langmead B and Salzberg SL: HISAT: A fast spliced aligner with low memory requirements. Nat Methods 12 357-360, 2015.

26. Roberts A, Trapnell C, Donaghey J, Rinn JL and Pachter L: Improving RNA-Seq expression estimates by correcting for fragment bias. Genome Biol 12: R22, 2011.

27. Trapnell C, Williams BA, Pertea G, Mortazavi A, Kwan G van Baren MJ, Salzberg SL, Wold BJ and Pachter L: Transcript assembly and quantification by RNA-Seq reveals unannotated transcripts and isoform switching during cell differentiation. Nat Biotechnol 28: 511-515, 2010

28. Anders S, Pyl PT and Huber W: HTSeq-a Python framework to work with high-throughput sequencing data. Bioinformatics 31: $166-169,2015$

29. Anders S and Huber W: Differential expression of RNA-Seq data at the gene level - the DESeq package. European Molecular Biology Laboratory (EMBL), Germany.

30. Zheng Q and Wang XJ: GOEAST: A web-based software toolkit for gene ontology enrichment analysis. Nucleic Acids Res 36: W358-W363, 2008.

31. Kanehisa M, Araki M, Goto S, Hattori M, Hirakawa M Itoh M, Katayama T, Kawashima S, Okuda S, Tokimatsu T and Yamanishi Y: KEGG for linking genomes to life and the environment. Nucleic Acids Res 36: D480-D484, 2008.

32. Xie Y, Zhu S, Song X, Sun X, Fan Y, Liu J, Zhong M, Yuan H, Zhang L, Billiar TR, et al: The tumor suppressor p53 limits ferroptosis by blocking DPP4 activity. Cell Rep 20: 1692-1704, 2017.

33. Tauriello DVF, Palomo-Ponce S, Stork D, Berenguer-Llergo A, Badia-Ramentol J, Iglesias M, Sevillano M, Ibiza S, Cañellas A, Hernando-Momblona X, et al: TGF $\beta$ drives immune evasion in genetically reconstituted colon cancer metastasis. Nature 554: 538-543, 2018

34. Kim BM, Hong Y, Lee S, Liu P, Lim JH, Lee YH, Lee TH, Chang KT and Hong Y: Therapeutic implications for overcoming radiation resistance in cancer therapy. Int J Mol Sci 16 : 26880-26913, 2015

35. Gao Z, Li Y, Wang F, Huang T, Fan K, Zhang Y, Zhong J, Cao Q, Chao T, Jia J, et al: Mitochondrial dynamics controls anti-tumour innate immunity by regulating CHIP-IRF1 axis stability. Nat Commun 8: 1805, 2017.

36. Cascone T, McKenzie JA, Mbofung RM, Punt S, Wang Z, Xu C, Williams LJ, Wang Z, Bristow CA, Carugo A, et al: Increased tumor glycolysis characterizes immune resistance to adoptive $\mathrm{T}$ cell therapy. Cell Metab 27: 977-987.e974, 2018.

37. Xiong W, Deng H, Huang C, Zen C, Jian C, Ye K, Zhong Z, Zhao X and Zhu L: MLL3 enhances the transcription of PD-L1 and regulates anti-tumor immunity. Biochim Biophys Acta Mol Basis Dis 1865: 454-463, 2019.

38. Lu C, Redd PS, Lee JR, Savage N and Liu K: The expression profiles and regulation of PD-L1 in tumor-induced myeloid-derived suppressor cells. Oncoimmunology 5: e1247135, 2016.

39. Garcia-Diaz A, Shin DS, Moreno BH, Saco J, Escuin-Ordinas H, Rodriguez GA, Zaretsky JM, Sun L, Hugo W, Wang X, et al: Interferon receptor signaling pathways regulating PD-L1 and PD-L2 expression. Cell Rep 29: 3766, 2019.

40. Shao L, Hou W, Scharping NE, Vendetti FP, Srivastava R, Roy CN, Menk AV, Wang Y, Chauvin JM, Karukonda P, et al: IRF1 inhibits antitumor immunity through the upregulation of PD-L1 in the tumor cell. Cancer Immunol Res 7: 1258-1266, 2019

41. Yang MQ, Du Q, Varley PR, Goswami J, Liang Z, Wang R, Li H Stolz DB and Geller DA: Interferon regulatory factor 1 priming of tumour-derived exosomes enhances the antitumour immune response. Br J Cancer 118: 62-71, 2018.
42. Lai Q, Wang H, Li A, Xu Y, Tang L, Chen Q, Zhang C, Gao Y, Song J and Du Z: Decitibine improve the efficiency of anti-PD-1 therapy via activating the response to IFN/PD-L1 signal of lung cancer cells. Oncogene 37: 2302-2312, 2018.

43. Wu A, Wu Q, Deng Y, Liu Y, Lu J, Liu L, Li X, Liao C, Zhao B and Song H: Loss of VGLL4 suppresses tumor PD-L1 expression and immune evasion. EMBO J 38: e99506, 2019.

44. Eschrich S, Zhang H, Zhao H, Boulware D, Lee JH, Bloom G and Torres-Roca JF: Systems biology modeling of the radiation sensitivity network: A biomarker discovery platform. Int J Radiat Oncol Biol Phys 75: 497-505, 2009.

45. Ohsugi T, Yamaguchi K, Zhu C, Ikenoue T, Takane K, Shinozaki M, Tsurita G, Yano H and Furukawa Y: Anti-apoptotic effect by the suppression of IRF1 as a downstream of Wnt/ $\beta$-catenin signaling in colorectal cancer cells. Oncogene 38: 6031-6064, 2019.

46. Wan P, Zhang J, Du Q and Geller DA: The clinical significance and biological function of interferon regulatory factor 1 in cholangiocarcinoma. Biomed Pharmacother 97: 771-777, 2018

47. Qi L, Li T, Shi G, Wang J, Li X, Zhang S, Chen L, Qin Y, Gu Y, Zhao W and Guo Z: An individualized gene expression signature for prediction of lung adenocarcinoma metastases. Mol Oncol 11: 1630-1645, 2017.

48. Zhou Y, Wang Q, Chu L, Dai W, Zhang X, Chen J, Zhang L, Ding $\mathrm{P}$, Zhang X, Gu H, et al: FOXM1c promotes oesophageal cancer metastasis by transcriptionally regulating IRF1 expression. Cell Prolif 52: e12553, 2019.

49. Jiang L, Liu JY, Shi Y, Tang B, He T, Liu JJ, Fan JY, Wu B, $\mathrm{Xu} \mathrm{XH}, \mathrm{Zhao} \mathrm{YL}$, et al: MTMR2 promotes invasion and metastasis of gastric cancer via inactivating IFN $\gamma / \mathrm{STAT} 1$ signaling. J Exp Clin Cancer Res 38: 206, 2019.

50. Meyer K, Kwon YC, Liu S, Hagedorn CH, Ray RB and Ray R: Interferon- $\alpha$ inducible protein 6 impairs EGFR activation by CD81 and inhibits hepatitis $C$ virus infection. Sci Rep 5: 9012, 2015.

51. Wu X, Wang S, Yu Y, Zhang J, Sun Z, Yan Y and Zhou J: Subcellular proteomic analysis of human host cells infected with H3N2 swine influenza virus. Proteomics 13: 3309-3326, 2013.

52. Hussein HA, Briestenska K, Mistrikova J and Akula SM: IFITM1 expression is crucial to gammaherpesvirus infection, in vivo. Sci Rep 8: 14105, 2018.

53. Cheriyath V, Kaur J, Davenport A, Khalel A, Chowdhury N and Gaddipati L: G1P3 (IFI6), a mitochondrial localised antiapoptotic protein, promotes metastatic potential of breast cancer cells through mtROS. Br J Cancer 119: 52-64, 2018.

54. Lui AJ, Geanes ES, Ogony J, Behbod F, Marquess J, Valdez K, Jewell W, Tawfik O and Lewis-Wambi J: IFITM1 suppression blocks proliferation and invasion of aromatase inhibitor-resistant breast cancer in vivo by JAK/STAT-mediated induction of $\mathrm{p} 21$. Cancer Lett 399: 29-43, 2017.

55. Shirai K, Shimada T, Yoshida H, Hayakari R, Matsumiya T, Tanji K, Murakami M, Tanaka H and Imaizumi T: Interferon (IFN)-induced protein 35 (IFI35) negatively regulates IFN- $\beta$-phosphorylated STAT1-RIG-I-CXCL10/CCL5 axis in U373MG astrocytoma cells treated with polyinosinic-polycytidylic acid. Brain Res 1658: 60-67, 2017.

56. Jung JJ, Jeung HC, Chung HC, Lee JO, Kim TS, Kim YT, Noh SH and Rha SY: In vitro pharmacogenomic database and chemosensitivity predictive genes in gastric cancer. Genomics 93: 52-61, 2009.

57. Gómez-Herranz M, Nekulova M, Faktor J, Hernychova L, Kote S, Sinclair EH, Nenutil R, Vojtesek B, Ball KL and Hupp TR: The effects of IFITM1 and IFITM3 gene deletion on IFNg stimulated protein synthesis. Cell Signall 60: 39-56, 2019.

58. Yang W, Tan J, Liu R, Cui X, Ma Q, Geng Y and Qiao W: Interferon-g upregulates expression of IFP35 gene in HeLa cells via interferon regulatory factor-1. PLoS One 7: e50932, 2012.

This work is licensed under a Creative Commons Attribution-NonCommercial-NoDerivatives 4.0 International (CC BY-NC-ND 4.0) License. 